\title{
ISSUES AND OPPORTUNITIES OF BULGARIAN AGRICULTURE UNDER THE CONDITIONS OF THE COMMON EUROPEAN MARKET
}

\author{
N. Kostadinova*, N. Petrova \\ Department of Management, Trakia University, Stara Zagora, Bulgaria
}

\begin{abstract}
Bulgaria takes an active position in the development and adoption of justified economical solutions for the transformation of the CAP of EU after 2013 in regards to its goals and priorities. The new situation calls for the necessity of in-depth studies of the undergoing changes in the state and possibilities for development of Bulgarian agriculture in the setting of the common European market.

The goal of the study is to analyze the problems and possibilities for the application of CAP of EU for the development of Bulgarian agriculture. To reach its goal the study need to go through a few steps:

- $\quad$ To analyze the state of Bulgarian agriculture and the problems with the application of CAP on its development;

- $\quad$ To uncover the possibilities for development of agriculture in Bulgaria under the influence of CAP of EU.

To reach the goals and complete the tasks in the study the methods of analysis and synthesis, the method of comparison, the axiomatic method, systematic and structural approach and statistical methods are used.

The forecasted outcome of the study is that the initial effect of the anointment of Bulgaria to the European Union and the application of the Common agricultural policies in our agricultural sector is insufficient.
\end{abstract}

Key words: agriculture, competitiveness, structural change, market

\section{INTRODUCTION}

Bulgaria has actively participated in the elaboration and implementation of economically founded resolutions for changes of the EU CAP in accordance with its objectives and priorities. New realities impose the necessity for profound research of the changes, occurring in the state and opportunities for development of Bulgarian agriculture under the conditions of a common European market.

The objective of this study is to investigate the issues and opportunities for the implementation of the EU CAP on the development of Bulgarian agriculture.

- To analyse the state of Bulgarian agriculture and the effects of CAP implementation on its development;

- To reveal the opportunities for the agriculture development in Bulgaria under the influence of EU CAP.

In order to achieve this goal and to solve the tasks the methods of analysis and synthesis, the comparative method, the axiomatic method, the

\footnotetext{
*Correspondence to: Nadka Kostadinova, Department of management, Trakia University, Stara Zagora, Bulgaria, tel: 042 699 416; fax: 042 699 416, email: nadya_kostadinova@yahoo.com
}

systemic and structural approach as well as statistical calculations are used.

Under the conditions of a common European market the elimination of possibilities for disloyal competition among trading partners is extremely important.The standard determined, which amounts to , respectively $25 \%, 30 \%$ and $35 \%$ from the standard in EU15 for the first three years and becomes equal to them in 2016 arranges Bulgarian agriculture in a nonequivalent status with the other member states. This correlation puts Bulgaria in an extremely nonequivalent position in competing with the countries from EU15.

In addition to the negative trends in Bulgarian agriculture during the previous period it is placed at disadvantage conditions of free competition, open market in the EU framework, receiving lower-rate subsidies in comparison with the other EU countries.

Actually whole subsectors such as vegetablegrowing, fruit-growing, viniculture and some other crops, as well as the animal husbandry (with the exception of poultry raising) whose subsidy rate determines to a great extent the unfavorable alternative of development, are constantly decreasing. Some of the perennial crops still survive, sold below their prime cost by their owners who expect better conditions. 
But these crops are not competitive at the national market either because of the strong competition of their highly subsidized European counterparts

At the common European market Bulgarian products compete directly with their Italian, French, Spanish, Portuguese and Greek counterparts whose subsidy rate is many times higher than the average per area or farm. For example, the difference for the subsidy rate in viniculture is 4-5 times bigger in those countries compared with the average for Bulgaria. On the one hand, the common rate of direct payments for 2009 reached only 35\% from that of EU15, and, on the other, the subsidies in the countries with a longer EU membership are 5-6 times different in the different regions and farms per unit area.

The influence of the differences in the subsidy rate, compared to that in countries in immediate geographic proximity, is particularly unfavorable. The average payments (per area) for Greece exceed many times those in Bulgaria. The proximity of these two countries and some similarities in the conditions and the structure of production considerably emphasize the extent of negative influence of these differences.

Estimated on a relative level, the subsidy, provided for Bulgarian agriculture by CAP, places Bulgarian producers into the conditions of disloyal competition with European ones.

During the last decade the share of the animal husbandry production from the total volume of agricultural production fell by almost $20 \%$, while only the decrease in the dairy husbandry is even higher - about $25 \%$.

The question about what kind of dairy husbandry will be developed in a middle-term aspect and what the future of the small dairy farms, which represent $90 \%$ of all farms in the country, has not been answered yet in Bulgaria.

Data from Figure 1 show that during the first decade of $21^{\text {st }}$ century the production cost from dairy husbandry is steadily decreasing by about $25 \%$ - on the basis of 2014 data, compared to 2000. At the same time the decrease in the value added in dairy husbandry corresponds to the total decrease in animal husbandry as a whole. The animal husbandry production decreased by about $42 \%$ for the 2000-2014 period with the biggest decrease in 2011, which is due to the sharp fall in the beef cattle raising .

The above mentioned shows that the whole animal husbandry sector experiences serious problems and there are no noticeable prospectives for recovery. The fall in the animal husbandry is due not only to decrease in the gross production in this branch. It is also the result of the changing structure of the agricultural production in the country in which the share of the grain sector increases and leads to the decrease in the relative share of the other subsectors. Meanwhile the number of the animals in the dairy husbandry was reduced by about $18 \%$ in the cattle and almost twice more in the sheep for the 2000-2014 period.

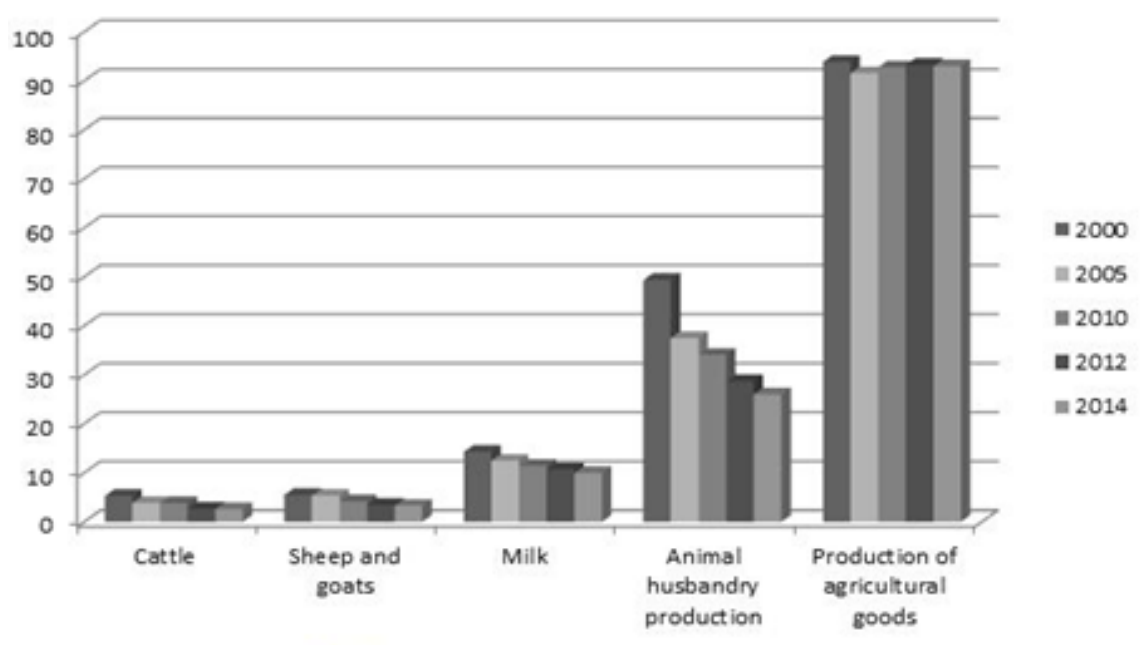

Source: Eurostat, (http://aposso.eurostat.ec.europe.eu) and our own calculations

Figure 1. Share of the cattle, sheep and goats products in the total animal husbandry production, \%

The number of Bulgarian farms complying with all the requirements for the production of cow milk with market access keeps growing, but their share remains about $4 \%$ of all the farms. Towards mid 2012 the farms of the $1^{\text {st }}$ category group (which have met the standards for building premises, equipment and quality of the raw cow milk) increased by $11 \%$ compared with the previous year, and the total number of cows, raised there, increased by $4 \%$.Meanwhile the $2^{\text {nd }}$ category group decreased together with the decrease in the animals, raised there. (Figure 2) 


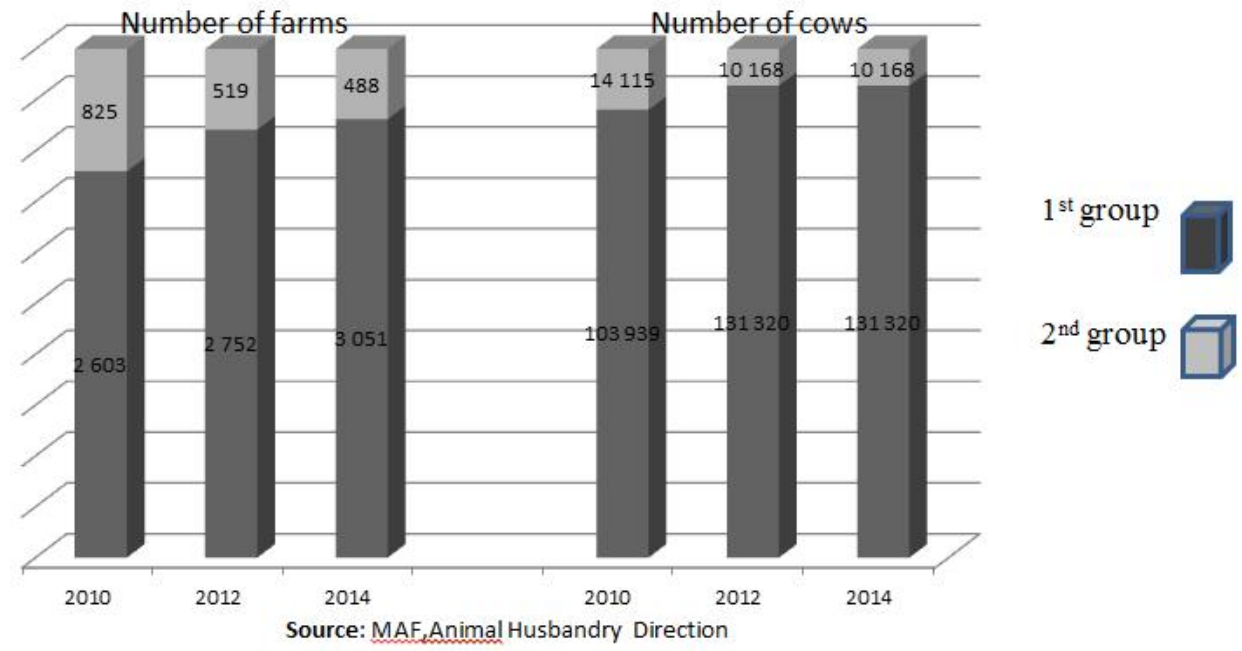

I

Figure 2. Number of categorized farms for the production of raw milk

A part of the small farms in the sector which have difficulties in complying with the European requirements for the yield of quality raw milk suspend their activities or redirect their efforts to other types of production raising of beef cattle, sheep breeding, goat breeding or direct sale. This turns out to be the best alternative for the small farms.

The total meat consumption is expected to rise from $84,5 \mathrm{~kg}$ per capita in 2006 to about 87,2 $\mathrm{kg}$ per capita in 2015 . The pork will remain the most preferred meat for the Europeans with an average share of $50 \%$, followed by the chicken which will increase its share to $28 \%$ (+1.5 pp).

Milk production in EU27 will slightly increase in a short-term period together with the rise of the production quotas.

The prospects for the agricultural income in the EU are positive - they have increased by about $18,1 \%$ for 2014 in real expression as well as per labor unit (Figure 3). Total incomes will attenuate the difference between EU15 and EU-10.For the 2006 - 2014 period the incomes rose by $7,1 \%$ in EU15, and by $31,2 \%$.- in EU10. In addition to the change of the price rates, the growth was triggered by the influence of the common agricultural policy, the common market and the considerable rise of the subsidies for the EU agricultural producers. Common prospects for the European agricultural markets and incomes during the next year are positive. Factors such as the macroeconomic environment (including oil price and the exchange rate dollar/euro), the policies for renewable energies, the way of the technological change, future climatic changes etc., will also influence, to a great extent, the future development of the agriculture and the agricultural markets in the EU.

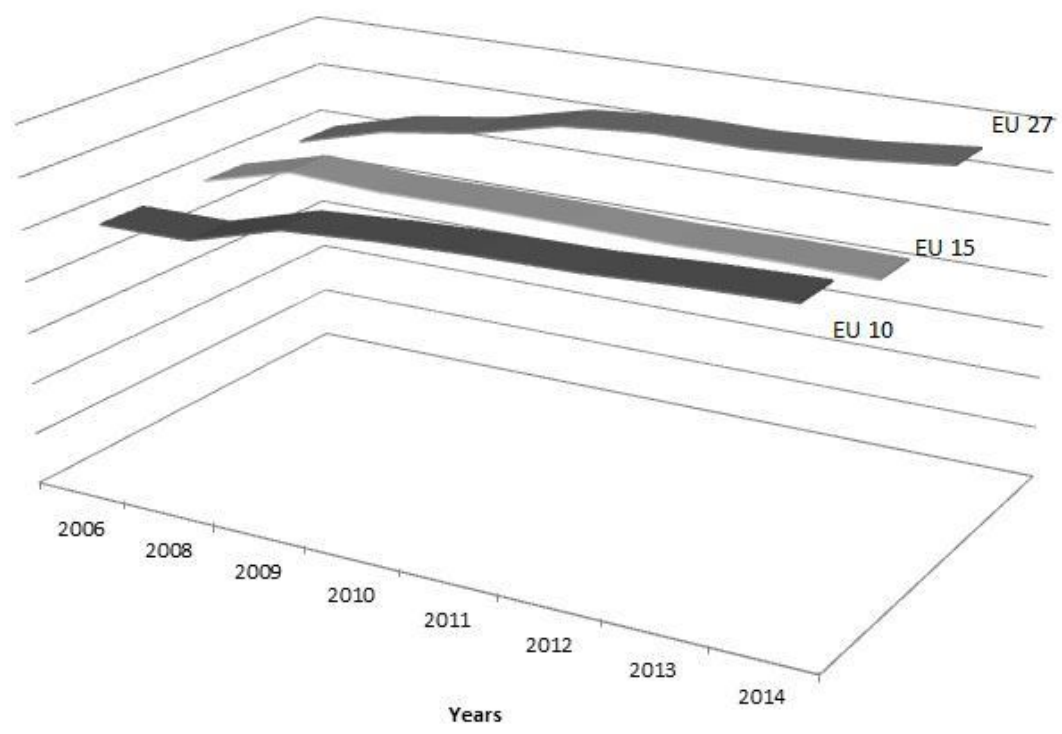

Source: European Commission, Chief Directorate of the agriculture and

Figure 3. Income from agriculture in EU 27, 2006-2014 
In 2013 the entrepreneurial income in Bulgarian agriculture increased by $23,7 \%$ and exceeded 3 billion BGN according to data from the 2014 Agrarian report. The unusual high growth is due to the subsidies received by agricultural producers. In 2013 they were by almost $40 \%$ more than those of the previous year. Financial means for supporting the branch are becoming a bigger and bigger part of the farmers' incomes with, respectively, $54,5 \%$ of the entrepreneurial income in the branch for 2013, 48,8\% for 2012 and 36,7\% for 2011 .

The gross value added, produced by the agriculture, amounted to more than 3,3 billion BGN with an increase by $1,9 \%$.

Large-scale farmers and the leaseholders have shared a bigger part of their incomes with their employees. The costs of the agricultural firms for salaries and insurance have risen by $11,8 \%$ in comparison with those of 2012 and have reached 616 million $\mathrm{BGN}$.

People who rely on incomes from lending cultivation lands have received less income. The leaseholders have reduced the ground rent amount and in 2013 the total sum paid has decreased by $7,4 \%$ compared with 2012 . Land owners have received a total of 759,8 million BGN.

The opportunities for the development of Bulgarian agriculture are inextricably bound up with the EU CAP after 2014.

The main scheme for supporting agricultural producers keeps on being per a hectare of agricultural land, non related to production. As of 2014 the European Commission has introduced a unified scheme for direct payments in the whole EU called Basic Payment Scheme. It is implemented in virtue of payment rights, distributed at a national or regional level to the farmers on the basis of their admissible hectares during the first year of the scheme implementation - 2014. In order to receive payment rights for 2014 farmers must have applied for support in 2011 in the framework of the Single Payment Scheme (SPS) and to meet the requirements for an active farmer. Rights to payment from the national reserve can be granted to farmers, aged below 40, who have begun their activities during the last 5 years and did not apply in the framework of SPS in 2011. The environmentally friendly characteristics of CAP guarantee that all farmers ensure benefits for the environment and the climate in their everyday activities beyond the limits of the requirements for cross compliance. For this purpose the EC considers that $30 \%$ from the direct payments have to be related to activities of common implementation such as: crop diversification, maintenance of lawns and environmentally friendly areas.

The maintenance of environmentally friendly areas introduces the requirement stipulating that at least $7 \%$ of the hectares, meeting the support requirements, have to be environmentally friendly such as lie fallow land, terraces, landscape particularities, buffer strips and afforested areas in the framework of the Program for the development of rural areas (PDRA).

In the framework of the CAP Second pillar the opportunity for supporting the mountain areas and areas with natural limitations, different from the mountain ones is preserved as well as the opportunity for supporting endangered local animal breeds. Mountain areas will remain the same, but areas with natural limitations will have to be redefined. A transit decreasing support is provided for the dropped out areas.

On the basis of the package,suggested for Bulgaria in the regulations draft on the direct payments through implementing the obligatory schemes (green payments - 30\% from the direct payment package, young farmers $-2 \%$ from the package and $7,5 \%$ from the package at a flat payment of 1000 Euros for a small farm ) when the full package for Bulgaria is achieved and after the convergence process for the 2017-2020 period the estimated value for the payment per a hectare to farmers, meeting the requirements for support in the framework of the Single payment scheme and complying with the requirements for green areas, will be 195 Euros/hectare(38BGN/decare).

Sectors in which production bound support can be implemented are the following: grain crops, oleaginous seeds, protein crops, legumes, flax, rice,hemp shell fruit, potatoes, starch,milk and dairy products, seeds, sheep and goat meat, beef and veal, olive tree, silk worms, hops, dry forage, sugar beet, sugar cane, chicory, fruit, vegetables and trees with a short rotation cycle. The list is exhaustive, so, support for other sectors outside this list cannot be provided.

A very important requirement is that the production bound support is granted only to sectors which are economically vulnerable or of particular importance because of economic, social or ecological reasons and as an only stimulus for maintaining the present production levels.

The budget for the production bound payments for all member states,including Bulgaria, which have implemented the Single payment scheme until 2013 on the grounds of a national 
resolution amounts to $10 \%$ from the direct payment package. For Bulgaria this will mean an opportunity for a bound support in the framework of 80 million Euros annually.

\section{CONCLUSIONS}

As a result of the study of the state of Bulgarian agriculture the following conclusions can be drawn:

- The EU membership of Bulgaria has not caused drastic changes in the agriculture. As a whole, the agricultural production has been stabilized, but on a low basis.

- The support in the framework of the EU CAP has led to an uneven modernization and development of the subbranches and sectors in the agriculture.

- The introduction of direct payments is a considerable, but insufficient support to the farmers' incomes. The direct payment rates in Bulgaria still amount to $40 \%$ from the average rate of those in Europe and this fact determines, to a great extent, the difficulties in the competitive power of the farms.

- As a whole the way of distribution of subsidies /direct payments and additional payments at a national level/ does not stimulate the manufacturing of products for which Bulgaria offers a lot of favorable, specific conditions products with a national identity, with better taste qualities than those of other countries in and outside the EU and which have been a traditional part of the agrarian export.

On the basis of the survey made of Bulgarian agriculture state the following opportunities for its sustainable development can be outlined:

- increase in the farm number and the average productivity ;

- increase in the labor productivity and reduction of the costs for unit labor, enhancing the farmers' educational level;

- modernization of farms by improving their necessary equipment, enhancement of the mechanization and the innovation activity;

- enhancement of the breeding and improvement activities, the health veterinary control and the treatment of animals;

- improvement of the product quality and hygiene, protection of the environment;

The opportunities outlined can be implemented by taking the following measures:

- changing the model of the agrarian policy which should be aimed at the development of the traditional and biological agriculture. European support payments are granted to the family farms and their cooperatives;

assimilation and use to the maximum of the enormous potential of EU agricultural programs;

organisation of a larger-scale
information campaign on the farmers'
opportunities to benefit from the European

structural funds in order to put in practice investments which will increase their efficiency and competitive power;

development of the state policy and the financial support to the animal husbandry so that it can participate more actively in the European market through advertising, exhibitions, fairs, etc.

- revival of original Bulgarian breeds, technologies and products which, to a great extent, reflect specific natural conditions in particular areas of the country;

elaboration of mid-term national strategies for the development of agriculture which should take into consideration the competitive advantages of Bulgarian goods at the European market;

Bulgarian agriculture has the potential for developing in the future, but this development must be complied with the European legislation requirements - aimed at the enhancement of the raw products and produce, offered on the market as well as at the sustainable financial support in the respective sectors.

\section{REFERENCES}

1. Agrarian report, (2005-2014), MAF, Republic of Bulgaria

2. Koteva, N, Kr. Kaneva, : The competitive power of the agricultural farms at the accession of Bulgaria to the $\mathrm{EU}$, journal Economy and management of agriculture, 51, issue.5, S, 2006, p.31

3. Popov, R., B. Ivanov: Effect from the implementation of the EU Common Agrarian Policy on the agriculture and the rural areas, Economy and management of agriculture journal, 54, issue3,S., 2009, pp.99, 102, 104

4. Slavova Y. and al., Competitive power of the agrarian products on the domestic and international market, IAI, S., 2006, cp.26-32

5. Stoynav, N.,: The animal husbandry during the period of European integration, NCAC, IAE, S, 2008, p.4, 57-60

6. Statistical hadbook 2010, 2011, 2012, NSI, S

7. Regulation on conditions and procedures for selection, implementation and monitoring of promotional programs for agricultural products and foodstuffs 2012 .

8. Mitova, D., B.Ivanov, Animal husbandry under the conditions of CAP implemenation, AA, IAI, S., 2013, .6-16; 28, 39, 61.

9. Popov P., M.Atanasova, Y.Slavova, Effects from the EU CAP implemenation on Bulgarian agriculture,AA,IAI,S.,2013, p.5,48.

10. European Commission: European Economy: annual economic report, 1993

11.http://www.dfz.bg,2013,State fund agriculture

12. http://ec.europa.eu/agriculture. 2013

13.http://www.sme.government.bg, 2013

14. www.fermer.bg, September, 2013

15. www.agronet.bg, September, 2013 
